\title{
Ramon Llull y el Discurso de Juan de Herrera
}

\author{
Mariano Carbonell Buades
}

Ramon Llull y el «Discurso» De Juan de Herrera

\section{Resumen}

La celebración del Any Llull (2015-2016), que conmemora el séptimo centenario del fallecimiento de Ramon Llull (también castellanizado como Raimundo Lulio), es una excelente ocasión para revisar algunos tópicos historiográficos. En particular, este artículo propone una reflexión sobre el verdadero alcance del lulismo de Juan de Herrera, el famoso arquitecto de El Escorial, a partir de tres elementos de juicio complementarios: su tratado llamado Discurso sobre la figura cúbica, el carácter excepcional de su biblioteca, con unos cien títulos lulianos sobre un total de cuatrocientos, aproximadamente, y su implicación personal en los prolegómenos del frustrado proceso de canonización del sabio mallorquín.

\section{Raymond Lully and the “Discurso” of Juan de Herrera}

\section{Abstract}

The celebration of Llull Year (2015-2016), commemorating the seventh centenary of the death of Ramon Llull (anglicised Raymond Lully), represents an excellent opportunity to review some historiographical topics. In particular, this paper offers a reflection on the true scope of the Lullism of Juan de Herrera, the famous architect of El Escorial, based on three complementary elements: his treatise entitled Discurso sobre la figura cúbica; the exceptional character of his library, with around one hundred Lullist titles among some four hundred books, and his personal involvement in the early stages of the frustrated process of canonization of the wise man from Majorca.

Carbonell Buades, M., «Ramon Llull y el Discurso de Juan de Herrera», Acta/Artis. Estudis d'Art Modern, 4-5, 2016-2017, págs. 13-26

Palabras Clave: Juan de Herrera, Raimundo Lulio, El Escorial, tratados renacentistas, bibliotecas renacentistas

KEYworDs: Juan de Herrera, Raymond Lully, El Escorial, Renaissance treatises, Renaissance libraries 


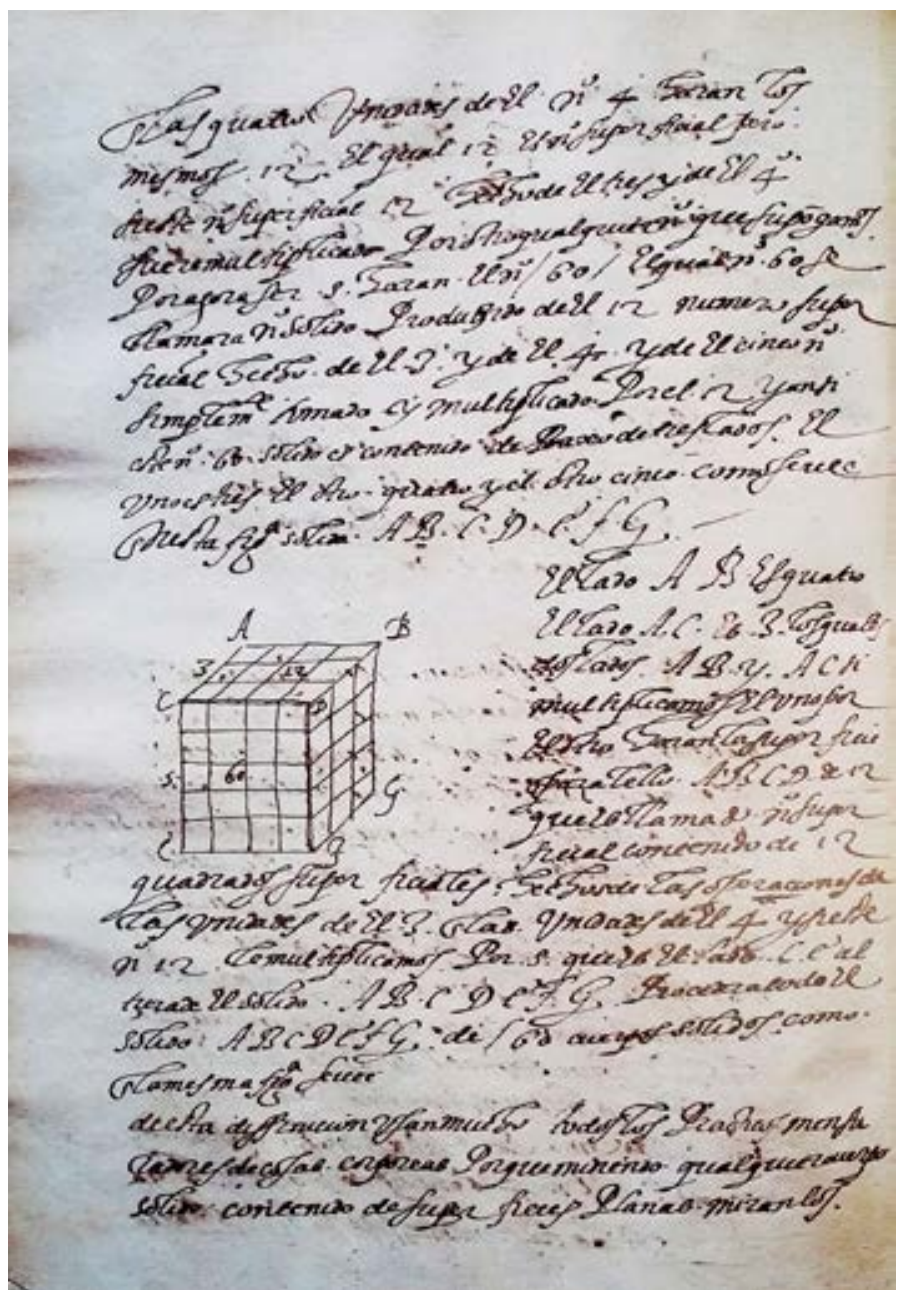

Digues, foll: quina cosa és meravella?

Respòs: Amar més les coses absents que les presents; e amar més les coses invisibles incorruptibles, que les vesibles corruptibles.

RAMON LLULL, Llibre d'amic e amat

Que Juan de Herrera sea el autor del célebre y luliano Discurso sobre la figura cúbica - también llamado Tratado del cuerpo cúbico con algunas figuras que es necesario penetrar y entender para la penetración de dicho cubo o, indistintamente, Tratado de la figura cúbica, útil y necesario para entender los principios de las cosas naturales y sus excelentes y admirables operaciones, máxime según el arte de Raimundo Lulio- ${ }^{1}$ no es un hecho probado de manera fehaciente, aunque todos los expertos, tanto lulistas como herrerianos, se muestran unánimes en la autoría, a pesar de que hasta ahora solo haya podido deducirse del mismo texto (ilustración 1). ${ }^{2}$ Como es bien sabido, el descubrimiento fue obra de Jovellanos en 1806, durante su cautiverio en el castillo de Bellver. El ilustrado gijonés explica los avatares del hallazgo en un erudito apéndice («Advertencia sobre él») añadido a la copia que mandó realizar al secretario Manuel Martínez Marina. ${ }^{3}$ Recuerda que, leyendo unas notas inéditas del cisterciense y

1. Juan de Herrera Discurso sobre la figura cúbica, Biblioteca del Colegio Oficial de Arquitectos de Madrid (colección J.M. Marañón). lulista mallorquín Antoni Ramon Pasqual, topó con esta frase: «Tengo un manuscrito sobre la figura cúbica del célebre Juan de Herrera, arquitecto, muy querido del señor rey don Felipe II, y en todo él procede por el arte Lulliana». ${ }^{4}$ Intrigado, Jovellanos pidió permiso para consultar y

1. Las dos copias más antiguas y conocidas se conservan en la biblioteca del monasterio de El Escorial (BME, d.III.25, fols. 111-153; BME, g-IV-39, fols. 20-79), pero también las hay en la del Colegio de Arquitectos de Madrid (COAM, FA15, Biblioteca de Marañón, XVI-11) y en la de Menéndez Pelayo de Santander (BMP, M-72, digitalizada y accesible en línea). Esta última coincide en los detalles con la versión de Jovellanos, mientras que la de Madrid parece concordar con el ejemplar que perteneció a Juan Bautista Labaña, primer catedrático de la Academia de Matemáticas fundada por Juan de Herrera bajo los auspicios de Felipe II. Otra copia se conserva en la Biblioteca Nacional de Roma, Fondi minori 2014, fols. 28-41. Hasta ahora las ediciones modernas son tres: HERRERA, J. DE, Tratado del cuerpo cúbico conforme a los principios y opiniones del «Arte» de Raimundo Lulio hecho por Juan de Herrera [Rey PAstor, J. (ed.)]. Madrid: Plutarco, 1935; idem, Discurso del Sr. Juan de Herrera aposentador mayor de S. M. sobre la Figura cúbica [Simons, E.; Godoy, R. (eds.)]. Madrid: Editora Nacional, 1976; idem, Sobre la figura cúbica [ARRATE PeÑA, M. (ed.)]. Santander: Universidad de Cantabria - Ayuntamiento de Camargo, 1998.

2. La excepción corresponde a PoRtabales Pichel, A., Los verdaderos artífices de El Escorial y el estilo indebidamente llamado herreriano. Madrid: Gráfica Literaria, 1945, pág. 155, que atribuye el texto a Juan Bautista de Toledo sin aportar ningún argumento convincente.

3. Inmediatamente el texto fue remitido a Ceán Bermúdez, al canónigo de Tarragona Carlos González de Posada, al arzobispo de Tarragona Romualdo Mon y a Francisco Javier de Cienfuegos, sobrino de Jovellanos y por entonces canónigo de Sevilla. El comentario de Jovellanos fue reproducido íntegramente en la edición del Discurso de 1976, pero los primeros parágrafos ya habían sido publicados por LLAGUNO Y AMIROLA, E., Noticia de los arquitectos y arquitectura de España desde su restauración. Madrid: Imprenta Real, 1829, vol. II, págs. 366-368, apéndice documental a la biografía de Juan de Herrera.

4. En realidad, parece que Jovellanos se refiere a una frase del padre Pasqual en su Descubrimiento de la aguja náutica, de la situación de la América, del arte de navegar y de un nuevo método para el adelantamiento en las artes y ciencias. Disertación en que se manifiesta que el primer autor de todo lo expuesto es el Beato Raymundo Lulio, Mártir y Doctor Iluminado, 
copiar el manuscrito, aportando detalles significativos: que ocupaba setenta y ocho hojas, que estaba escrito con suma diligencia y en buen papel, infolio, que contenía gran número de figuras matemáticas, «dibujadas con la mayor limpieza y primor, y con tintas roja, violada y negra, que también esta circunstancia era requerida por la materia del discurso» — habrá que suponer, pues, que, más allá de la calidad del dibujo, el color era importante para comprender adecuadamente los cuerpos geométricos $-{ }^{5}$ y que en el frontispicio constaban autor y título, Discurso del señor Juan de Herrera, aposentador mayor de su majestad, sobre la figura cúbica. Después, incomprensiblemente, el códice original desapareció sin dejar rastro. Si fue devuelto por Jovellanos, como así parece, habrá que pensar que el extravío se debió a la Desamortización de Mendizábal. Y es que en 1843 el monasterio de Santa María la Real de Palma fue vendido a particulares, excepto la iglesia, que permaneció abierta al culto.

Jovellanos señalaba que desconocía las vicisitudes anteriores del manuscrito, pero suponía que pudo haber llegado al monasterio cisterciense a inicios del siglo XVIII. Esto lo deducía de una inscripción con letra más moderna conservada en el dorso de la primera página, donde constan una fecha (12 de diciembre de 1703) y un nombre (Don Vincencio Squarzafigo). Es decir, Vincencio Bernabé Squarzafigo Centurión y Arriola (1670-1737), uno de los fundadores y primer secretario de la Real Academia de las Letras, encargado de las voces de matemáticas del Diccionario de Autoridades. Nacido circunstancialmente en Cádiz, era hijo de un banquero italiano establecido en Madrid, agente de la firma genovesa Spínola; formado en el Colegio Imperial de la capital, tuvo solo dos hermanos, ambos jesuitas. Eran proverbiales su condición de célibe, la misantropía y una salud delicada. La necrológica dictada por un colega académico acentuaba su interés por la geometría y la astronomía: «encerrado en celestes conmensuraciones le crecerá elevado a observar los celestes movimientos. Hablen tantos cálculos de su mano, hablen tantas observaciones hechas por su curiosa aplicación». ${ }^{6} \mathrm{Al}$ morir Squarzafigo, su biblioteca, integrada por unos mil volúmenes, fue adquirida por la Real Academia, pero esto no es óbice para que el manuscrito de Herrera pudiera haber sido vendido con anterioridad, lo que explicaría su traslado a la isla hacia 1750, coincidiendo con el viaje del citado padre Pasqual a la Corte, enviado por los Jurados de Mallorca con el objetivo de informar sobre los obstáculos que ponían los dominicos a la doctrina y culto lulianos. No parece una hipótesis descabellada que fuera el mismo padre Pasqual quien se hiciera con el original en Madrid para los cistercienses de Mallorca o, sencillamente, para su uso personal, ya que fue catedrático de filosofía luliana durante más de cincuenta años. Al pie de la portada de la copia de la Biblioteca Menéndez Pelayo aparece aún otro nombre, «es de don Sevastian de Sassiola y Arançibía», a quien razonablemente podemos identificar con Sebastián de Sasiola y Arancivía o Arancibia (a veces, invirtiendo los apellidos; otras, suprimiendo uno de los dos), nombrado almirante de la flota de Tierra Firme en 1593 por los servicios prestados en la Armada Real contra los ingleses y por su «buen seso». Se puede conjeturar que Sasiola fuera el primer propietario del manuscrito, o uno de los primeros, pero por ahora no me ha sido posible obtener más información al respecto.

A la muerte de Herrera se levantó el inventario de bienes, incluidos los libros, con la correspondiente tasación, aunque «no se tasaron los de rreymundo lulio porque no se avían de

con un apéndice de la enseñanza pública, de los progresos de la literatura y otros puntos históricos pertenecientes a Mallorca. Madrid: Imprenta de Manuel González, 1789, pág. 85: «Tengo un manuscrito sobre la Figura cúbica, cuyo Autor es Juan de Herrera, Arquitecto mayor del Señor Don Felipe II; y en él se sirve exactamente del Arte Luliana para todo lo que discurre en el asunto", es decir, las matemáticas.

5. En efecto, se dice en el Discurso, «... y púsolos Raymundo en tres triángulos; uno bermellón, que es diferençia, concordançia, contrariedad [...]. El segundo es colorado y tiene al prinçipio medio y fin, que son tres concordantes, y el tercero triángulo es amarillo».

6. CARriscondo Esquivel, F.M., «Vincencio Squarzafigo», Boletín de la Real Academia Española, 294, 2006, págs. 241-294; idem, «Noticia primera de Vincencio Squarzafigo (1670-1737)», en Roldán PÉREz, A. (ed.), Caminos actuales de la Historiografía Lingüística, Actas del V Congreso Internacional de la Sociedad Española de Historiografía Lingüística, 7-11 de noviembre de 2005, Murcia. Murcia: Universidad de Murcia, 2006, págs. 363-374. 
vender ni avía licencia para ello», ya que el rey los exigía para la biblioteca de El Escorial, adonde en efecto fueron a parar. Sin embargo, el Discurso no era obra de Lulio, sino del propio Herrera. Se lee en el inventario «Discurso de el cubo hecho por el mismo Juan de Herrera». Stricto sensu, «hecho», no escrito, cuando para otros ítems el mismo documento precisa «un legajo de papeles de cartapazios y libros manuescriptos que contiene dibersas cosas de mathemáticas escriptas de mano de Juan de Herrera y otros» 0 «un quaderno que contiene dibersas cosas de las mathemáticas sobreescripto de Juan de Herrera». ${ }^{7}$ Sin embargo, nada impide que podamos interpretar «hecho» como sinónimo de escrito, producido, elaborado o realizado. En realidad, Jovellanos dudó en un primer momento de la legitimidad del manuscrito hasta que Ceán Bermúdez le remitió una carta original del arquitecto:

la cotejó con la del discurso y comprobó ser también éste de su puño [...]. Todo me lo remitió entonces a Sevilla, de lo qual he dado ya cuenta a nuestra Academia de la Historia en la vida de Juan de Herrera, que escribí de su orden. ${ }^{8}$

Dejando de lado la prueba caligráfica, al menos otros tres argumentos permiten defender la autoría de Herrera. En todo caso, no dejan lugar a duda sobre la fascinación que en él ejercía el sistema filosófico luliano: la voluntad de fundar una memoria para la enseñanza del cristianismo de acuerdo con la doctrina luliana en el valle de Valdáliga, su lugar de nacimiento, según dispone en el segundo testamento conocido, fechado el 20 de febrero de $1579 ;{ }^{9}$ la ingente proporción de libros lulianos en su biblioteca, y una directa implicación en la incoación del frustrado proceso de beatificación o causa pía luliana. El testamento citado es muy ilustrativo de la fe del converso con que el arquitecto sostenía la doctrina del mallorquín:

De toda la demás hazienda que me quedase, ansí de los bienes que tengo yo y poseo y de los que se me debieren por qualquier bía y manera que sea, quiero y es mi voluntad que de todo ello se haga una memoria en que sea nuestro Señor más servido y loado [...], la qual dicha memoria sea de cosa que los del dicho valle se puedan aprovechar en dotrina y saber que con ello conozcan y entiendan

7. Ruiz de ArCaute, A., Juan de Herrera. Madrid: Instituto Juan de Herrera, 1997 (1936), pág. 150 y ss.; CERVERA VerA, L., Inventario de los bienes de Juan de Herrera. Valencia: Albatros, 1977. René Taylor ya notaba esta anomalía descriptiva, dando más importancia al hacer, en el sentido de elaborar o fabricar, que al escribir, ya que esta última fórmula podría indicar un simple trabajo de copista; véase TAYLOR, R., Arquitectura y magia. Consideraciones sobre la idea de El Escorial. Madrid: Siruela, 1992, pág. 108, n. 12.

8. Ceán Bermúdez, J.A., Memorias para la vida del Excmo. Señor D. Gaspar Melchor de Jovellanos y noticias analíticas de sus obras. Madrid: Fuentenebro, 1814, pág. 325.

9. Cervera Vera, L., Documentos biográficos de Juan de Herrera. I (1572-1581), «Colección de documentos para la Historia del Arte en España», vol. I. Madrid-Zaragoza: Real Academia de Bellas Artes de San Fernando - Museo e Instituto de Humanidades «Camón Aznar», 1981, págs. 367-387; idem, Documentos biográficos de Juan de Herrera. II (1581-1596), «Colección de documentos para la Historia del Arte en España», vol. IV. Madrid-Zaragoza: Real Academia de Bellas Artes de San Fernando - Museo e Instituto de Humanidades «Camón Aznar», 1987; véase en relación con CERVERA VERA, L., Los cuatro testamentos otorgados por Juan de Herrera. Santander: Fundación Obra Pía Juan de Herrera, 1997. Las dos transcripciones del segundo testamento no son rigurosamente coincidentes. Reproducen un fragmento de la primera versión WILKINSON Zerner, C., Juan de Herrera, arquitecto de Felipe II. Madrid: Akal, 1996 (New Haven - Londres: Yale University Press, 1993), pág. 186, n. 49; y Bustamante García, A., «Juan de Herrera», Altamira, 52, 1996, págs. 7-41, en particular pág. 39, n. 27; y de la segunda, ARAmburu-Zabala, M.A., Juan de Herrera. Madrid: Fundación Ignacio Larramendi, 2013, pág. 139, obra en formato electrónico, disponible en http://www.larramendi.es/en/catalogo_imagenes/grupo.cmd?path=1021466 En el tercer testamento, dictado el 6 de diciembre de 1584, estando enfermo, Herrera establecía numerosas mandas pías, pero sustituía la fundación luliana por dos capellanías en San Juan de Maliaño y una obra pía destinada a subvenir estudiantes pobres y dotar doncellas huérfanas. Por entonces acababa de nacer su hija Lorenza, a quien nombró heredera universal; véase LLAGUNO Y Амírola, E., Noticia de los arquitectos y arquitectura de España desde su restauración, vol. II. Madrid: Imprenta Real, 1829, págs. 342-357; VAQUERIZO GIL, M., «Transcripción del tercer testamento de Juan de Herrera», Altamira, 52, 1996, págs. 297-315. Para la transcripción íntegra de una copia certificada de 1875, véase Homenaje a Juan de Herrera. Santander: Librería Estudio, 1988, pág. 119 y ss. Un cuarto y definitivo testamento fue presuntamente redactado el 13 de enero de 1597, poco antes de morir, aunque no se ha localizado. En todo caso, fue invalidado a raíz del pleito incoado a su muerte. Sobre este último tema véase GARcía TAPIA, N., «Documentos sobre Juan de Herrera», Altamira, 52, 1996, págs. 43-66. 
de ser cristianos y como se a de servir y loar nuestro Señor, que por falta de enseñadores de esto biven en toda ésta muy brutal y ignorantemente, de que es tener mucha lástima y compasión, y pido y encargo al señor doctor Isidro $\operatorname{Caxa}^{10}$ que, si tal que de ella se pueda sacar algún fruto que sea en servicio de nuestro Señor, que dé horden como de la dicha mi hazienda se constituya y hordene alguna lectura de la dicha dotrina, porque yo he sido afiçionadíssimo al dicho autor Raymundo por la piedad y buen çelo que en él e conosçido, de que todos sean grandes siervos de el Señor.

No se sabe cuándo despertó el ferviente lulismo de Herrera, pero podemos especular que debió ser entre 1576 - ya que en el primer testamento redactado aquel año, mancomunado con su primera mujer, María de Álvaro, no hay rastro de tan particular devoción, aunque, bien mirado, esto no es óbice para que ya se hubiera iniciado en los misterios lulianos- y 1584, cuando establece la manda pía en tierras montañesas. Se ha avanzado que pudo ser a través del círculo alcalaíno $^{11} \mathrm{o}$, cosa harto improbable, por influencia de Juan Bautista de Toledo e, indirectamente, del lulismo italiano. ${ }^{12}$ En todo caso, fue con anterioridad a su nombramiento como aposentador mayor de Palacio, título con el que firma el Discurso, cosa que tuvo lugar en 1579. Por otra parte, en el cuadro de enseñanzas de la Academia de Matemáticas, fundada en 1582, figuraba el arte luliana por expreso deseo del rey. ${ }^{13}$ Son varios los posibles introductores de Herrera en materia lulista, para empezar, el mismo Felipe II, que se convirtió en el gran adalid de la ortodoxia teológica de Llull y el principal impulsor de la frustrada canonización. Los primeros libros que regaló a El Escorial para fundar la biblioteca llegaron entre 1565 y 1568, y ya en 1576 cedió, entre más de cuatro mil quinientos volúmenes, al menos cinco textos de contenido alquímico atribuidos a Llull, erróneamente, excepto uno. Los cronistas antiguos se hacían eco de estos intereses:

Por su gran sabiduría gustava [Felipe II] de leer los libros de Raymundo Lulio, Doctor, y Mártir, y por alivio de sus caminos los llevaba consigo en las jornadas que hazía, e iba leyendo en ellos; y en la librería del Escurial se hallan oy algunos rubricados de su propia mano. ${ }^{14}$

Precisamente para la jornada de Portugal (1580-1583), el canónigo mallorquín Joan Seguí le compuso una biografía de Llull. El testimonio del autor prueba la complicidad entre monarca y arquitecto:

Para lo qual, siguiendo yo la corte de la Magestad Cathólica del Rey Don Phelipe segundo deste nombre, que está en el Cielo, procuré muchas vezes con todas las veras que pude, assí de palabra como por memoriales, darle noticia deste hecho, y como su discreción y Real ingenio, ornado de tantas virtudes

10. Isidro Caja de la Jara, natural de la diócesis de Albarracín, se formó en Salamanca y en el Colegio Mayor de San Ildefonso de Alcalá de Henares, donde regentó la cátedra de artes entre 1565 y 1569. Felipe II lo destinó al Colegio de Párraces de El Escorial, donde fue catedrático de teología durante cuatro años, y en 1582 lo presentó a la mitra de Mondoñedo. Falleció en 1593; véase FlóREz, E., España Sagrada. Teatro geográfico-histórico de la Iglesia de España, vol. XVIII. Madrid: Antonio Marín, 1764, págs. 251-252; CAL PARDo, E., Episcopologio mindoniense. Santiago de Compostela: Publicaciones de Estudios Mindonienses, 2003, págs. 368-383. Se desconoce si el futuro obispo tenía intereses lulianos, pero quizá los pudo adquirir en Alcalá. Además del doctor Caja, Herrera nombraba testamentario a Juan de Minjares, aparejador de cantería en El Escorial.

11. Como mínimo tuvo relación con Honorato Juan, catedrático complutense, a quien conocía de Flandes, y que le encargó en 1562, por mandato del príncipe Carlos, la ilustración de una nueva transcripción de los Libros del saber de astronomía atribuidos a Alfonso X, cuyo original se guarda en la biblioteca de El Escorial. Sin embargo, no hay rastro de Llull en la librería conocida del obispo de Osma. Aun cuando una parte de la biblioteca fue vendida en almoneda, lo más lógico es que, de contener títulos lulianos, alguno habría ido a parar a El Escorial, ya sea a través de Felipe II, ya sea indirectamente a través de Diego Hurtado de Mendoza o Jerónimo Zurita, que adquirieron libros en dicha subasta; véase GonZALo SÁNCHEZ-MolERo, J.L., «La biblioteca de Honorato Juan (1507-1566), maestro de príncipes y obispo de Osma», Pliegos de Bibliofilia, 9, 2000, págs. 3-23.

12. TAYLOR, R., Arquitectura y magia..., pág. 108, n. 18.

13. Entre otros, Herrera, J. DE, Institución de la Academia Real Mathemática [Simón DíAZ, J.; Cervera VerA, L. (eds.)]. Madrid: Instituto de Estudios Madrileños, 1995; GARcía BARRENo, P., «Avatares de la Academia de Matemáticas de Felipe II», en Yeves, J.A. (ed.), Institución de la Academia Real Matemática. Madrid: Instituto de Estudios Madrileños, 2006, págs. 135-195.

14. Porreño, B., Los dichos y hechos del Rey Phelipe II llamado con justa razón el Prudente. Bruselas: Francisco Foppens, 1666, pág. 187. Existe una edición moderna de González Palencia, R. (ed.). Madrid: Saeta, 1942. 
con una inaudita inclinación a cosas de ciencias era tanta, no sólo quedó enterado del negocio, pero devotíssimo deste Santo varón y de sus obras y admirable Doctrina, tanto que las demás noches se entretenía en leer libros deste Santo, y en particular el Blanquerna, que con tanto artificio trata de Cinco estados del hombre, y en prueba desta su devoción se hallan en la Librería de San Lorenço el Real muchos libros deste Santo, rubricados de la Real mano de dicho Santo Rey y Señor nuestro. Y como siempre estava pensando en cosas buenas, no le estorvavan caminos, ocupaciones de negocios, estado y guerras, que no leyesse sus ratos, y platicasse cosas de doctrina. Y assí, marchando para la jornada de Portugal, me hizo entender, con la buena memoria de Iuan de Herrera, que gustaría de un breve discurso y relación de la vida y hechos del dicho admirable Doctor, lo qual hize con la brevedad que requería cosa hecha caminando. Y llegado en Lisbona, cabeça de Portugal, acabé dicha relación y la di en sus Reales manos, con la qual quedó tan afficionado a esta Santa doctrina que desde entonces ha hecho mil diligencias para que se lea, y para que con mayor diligencia se hiziesse ha escrito una y muchas vezes al Summo Pontífice porque con su autoridad se quite la siniestra opinión que deste Santo ha escrito Nicolás Eimeric, y que se hiziesse el processo para su canonización. ${ }^{15}$

Poco después, el también mallorquín Antonio Bellver, canónigo de la catedral y detentor de la cátedra luliana del Estudio General de Mallorca, redactaba una Apologia lullianae doctrinae adversus Nicholai Eymerici calumnias, dirigida a Sixto V y a Felipe II para hacer frente a la controversia nuevamente suscitada en Roma contra la doctrina luliana, sobre todo después de que en 1578 el canonista y futuro auditor de la Rota Francisco Peña reeditase el Directorium inquisitorum, y ello a pesar de que los padres conciliares de Trento habían aprobado en 1563 la salida de Llull del Índice. ${ }^{16}$ Entre los documentos aducidos, Bellver recuerda la sentencia contraria a Eimeric dictada en 1419 por Bernardo Bartolomei, obispo de Città di Castello y juez apostólico, en nombre del cardenal Ademaro, legado del papa Martín V, de la cual conocía dos copias; una la había visto reproducida en un libro publicado en Palma en 1604, mientras que la otra estaba en manos de Herrera, no fortuitamente:

Ítem transumptum authenticum Gabriel Vasquez Societatis Jesu tom 2. $1^{\mathrm{a}}$ pag. disp. 133. $\mathrm{n}^{\mathrm{o}}$ 10. testatur se vidisse et habuisse in Hispania a Joanne Herrera, Philippi 2. Regis architecto, ac in mathematicis litteris viro insigni,

una constatación más de la implicación del arquitecto en la defensa a ultranza de la ortodoxia luliana. ${ }^{17}$

Pero ya unos pocos años antes, el doctor Dimas de Miguel había preparado otra Apologia doctrinae lullianae, dirigida al futuro cardenal Gaspar de Quiroga, por entonces obispo de Burgos e inquisidor general del reino. ${ }^{18}$ Por la dedicatoria, la redacción se sitúa hacia 1573-1577,

15. Seguí, J., Vida y hechos del admirable Dotor y Mártyr Ramon Llull vezino de Mallorca. Palma de Mallorca: Gabriel Guasp, 1606, págs. 3v-4. El texto lo exonera de alquimista y aduce los privilegios favorables y los acuerdos sobre el tema del Concilio de Trento. Incluye también Lo desconhort, en traducción castellana de Nicolau de Pacs, impresa en Mallorca en 1540. La obra fue escrita en 1580. Poco después, Seguí fue enviado a Roma como agente de la causa pía.

16. Personalmente, Peña no sentía animadversión por la doctrina lulista; véase PÉREz MARTíNEz, L., «La causa luliana en Roma durante el reinado de Felipe II», Anthologica Annua, 10, 1962, págs. 193-249.

17. La Apologia de Bellver restó inédita, aunque contase con una censura previa de 1605 . Se conservan copias en la Biblioteca Vaticana y en la Pública de Mallorca (Ms. 1015, Ms. 1016; de este último ejemplar se ha sacado la cita, fol. 355). El jesuita aludido, Gabriel Vázquez (Belmonte, 1549 - Alcalá, 1604), estudioso de san Agustín, era profesor de teología en Alcalá y Roma. Atacó a Llull tanto por su argumentación trinitaria como por su posición sobre la necesidad de la Encarnación. En particular, Bellver alude a los Commentariorum ac Disputationum in primam partem S. Thomae, vol. II. Alcalá de Henares: Ioannis Gratiani, 1598, pág. 197: «cuius transumptum authenticum ego postea habui in Hispania a Ioanne Herrera Philippi Regis Secundi architecto, ac in Mathematicis literis viro insigni, in qua damnatur Aymericus». Sobre la sentencia de 1419, véanse PUIG I OLIVER, J. DE, «La sentència definitiva de 1419 sobre l'ortodòxia lul-liana. Contextos, protagonistes, problemes», Arxiu de Textos Catalans Antics, 19, 2000, págs. 297-388; REQUESENS I PIQUER, J., «Tres greuges històrics sanats o l'honor d'Orígenes, Feliu d'Urgell i Ramon Llull», Analecta Sacra Tarraconensia, 78-79, 2005-2006, págs. 11-46.

18. Blanco, P., «La Apología Luliana, del Dr. Dimas de Miguel, y el catálogo de las obras de Raimundo Lulio, del Dr. Arias de Loyola», La Ciudad de Dios, LXXVII, 1908, págs. 326-333, 412-420 y 590-596, y LXXVIII, 1909, págs. 319-324. El trabajo fue 
seguramente hacia el final del quinquenio, ya que parece anticiparse a la edición romana de 1578 del Directorio de Eimeric. Es muy improbable, por no decir imposible, que el partido lulista de Roma no estuviera al corriente de la empresa de Peña, protegido por Gregorio XIII y miembro de la comisión que preparaba la edición oficial del Corpus iuris canonici. ${ }^{19}$ El manuscrito del Dr. Dimas se conserva en la biblioteca de El Escorial. En principio, la fecha de redacción no tendría mayor importancia si no fuera porque el autor atribuía su pasión luliana a Juan de Herrera, al menos si nos fiamos del Discurso:

En mucho devo yo estimar la m[e]r[ce]d quel doctor Dimas me hace en deçir que por mi causa bino a penetrar la admirable arte lulliana porque careçiendo yo de todo género de estudios mal puedo abrir las puertas de una tan alta y tan poco conosçida doctrina y méthodo de saber.

Aún más, parece ser que fue el mismo teólogo quien sugirió a Herrera la idea de redactar el tratado:

Assí pues no sería la cosa perfecta sin su ser y obrar sobre dicho [cuerpo cúbico], pero tornando a lo que V.M. [Dimas de Miguel] me pide del cuerpo cúbico diré lo mejor que pudiere algo de lo que del penetro y entiendo, aplicándole a la declaraçión de la dicha arte Lulliana.

Poco se sabe del Dr. Dimas, sino que era doctor en artes y teología de la diócesis de Elna, que impartió doctrina luliana en Valencia —aunque se le prohibió en 1586- y en Alcalá —o al menos que lo intentó aquel mismo año-, y que poco después se trasladó a Roma, donde fue denunciado a la Inquisición por disponer de libros prohibidos, léase lulianos. Murió en 1588, después de pasar unos días en la cárcel. Herrera se mostraba crítico con la actitud poco diplomática de su amigo: «porque el Dr. Dimas dañó mucho en Roma y exasperó mucho con disputas sin tiempo ni coyuntura y no tan miradas como conviniera, y en otras partes, de manera que antes destruyó que edificó».. ${ }^{20}$ Sea como sea, Herrera tuvo que escribir el Discurso entre 1579 - cuando es nombrado aposentador-y 1588, año de la muerte del Dr. Dimas, aunque como ya se ha dicho su lulismo se remontaba a bastantes años atrás. De hecho, se nos hace cada vez más evidente que el catalizador de la euforia lulista que se desata en la Corte a finales de la década de 1570, cuya finalidad última sería el inicio del proceso de beatificación, es el mismo Herrera o, mejor dicho, el tándem formado por Felipe II y Herrera.

Del mismo círculo formaba parte Pedro de Guevara, considerado el primer representante de la tendencia enciclopédica en lengua vernácula del lulismo en Castilla. Parece ser que Guevara fue preceptor de las infantas Isabel Clara Eugenia y Catalina Micaela en las materias del Trivium. Según Cervera Vera, el arquitecto pudo conocer al licenciado porque este era obtentor de una capellanía instituida en la iglesia madrileña de San Ginés por la madrastra de su primera mujer, con quien estuvo casado entre 1571 y $1576,{ }^{21}$ pero parece más plausible que Gue-

\footnotetext{
amortizado, ya que también se publicó en el Bolletí de la Societat Arqueològica Lul-liana, XII, 1908-1909, págs. 193-197, 209-214, 228-232 y 241-244, y XIII, 1910-1911, págs. 45-47 y 122-126; y en la Revista de Archivos, Bibliotecas y Museos, XXIX, 1913, págs. 91-111 y 236-248. Finalmente, lo reeditó bajo el título de Estudios de bibliografía luliana. Madrid: Imprenta de la Revista de Archivos, Bibliotecas y Museos, 1916. El manuscrito se conserva en la biblioteca de El Escorial, integrado en un facticio que perteneció a Ambrosio de Morales (d-II-5, 1. $^{\circ}$, fols. 138r y ss.).

19. En este tema cabe destacar la implicación de Juan Arce de Herrera (Palencia, c. 1540 - Roma, 1590), doctor en derecho residente en Roma, consejero jurista del cardenal Fernando de' Medici, agente de negocios del duque de Alba y asesor de los Jurados de Mallorca en materia de defensa luliana en la curia. Se conservan cartas suyas dirigidas a Cosme I de' Medici y al cardenal Federico Borromeo. Este último reunió un notable fondo de manuscritos lulianos, quizá gracias al palentino, que hoy se conserva en la Ambrosiana de Milán.

20. Pérez Martínez, L., La causa luliana..., pág. 225. La frase aparece en un memorial dirigido por Juan de Herrera y Arias de Loyola a los Jurados de Mallorca en 1594.

21. Cervera Vera, L., María de Álvaro, primera mujer de Juan de Herrera. Madrid: Castalia, 1974; ídem, «Amistad de Juan de Herrera con el licenciado Pedro de Guevara», Boletín de la Institución Fernán González, 214, 1997, págs. 7-10.
} 


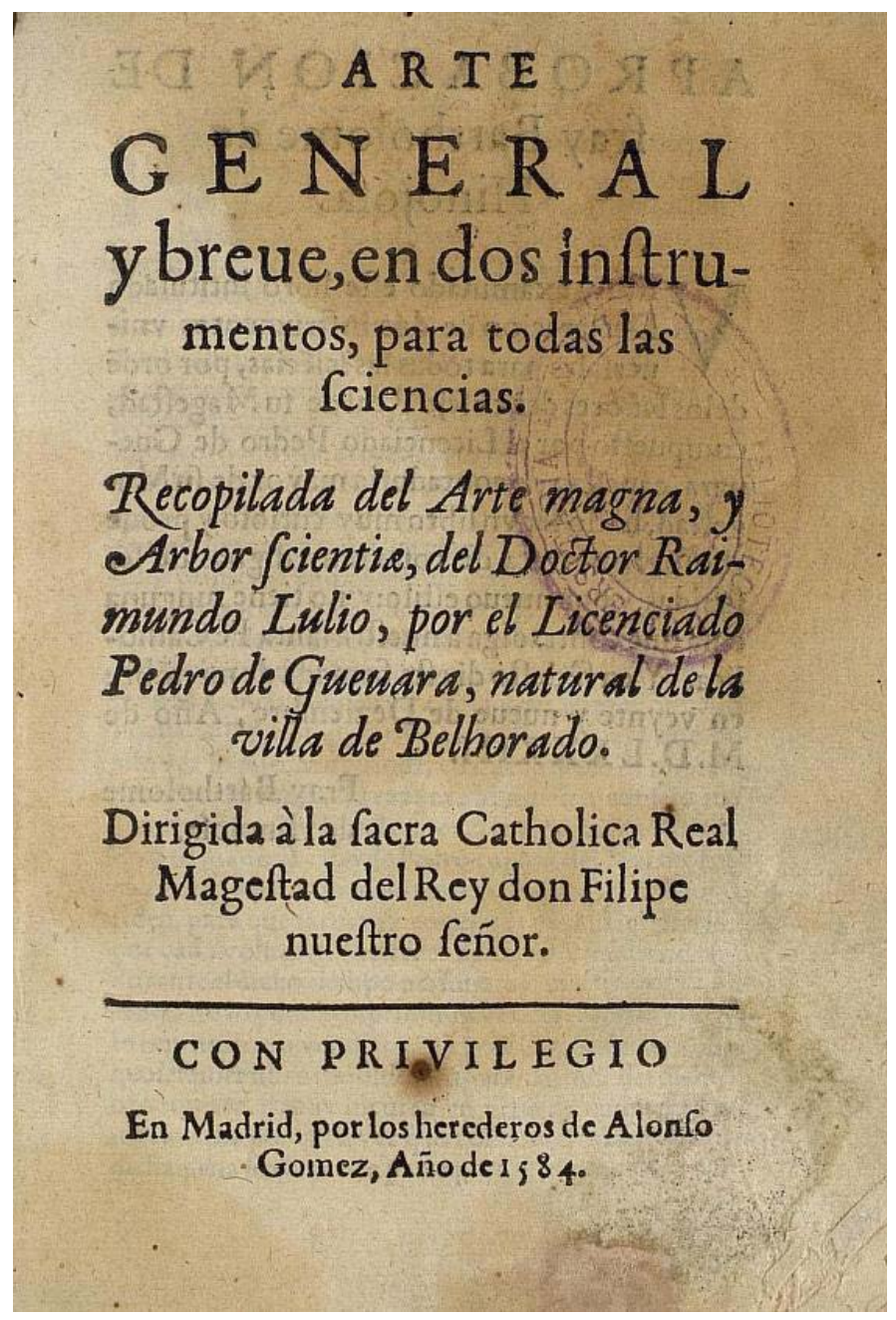

vara fuera presentado a dicho beneficio precisamente porque ya con anterioridad contaba con la protección de Herrera, quien había heredado bienes y patronatos eclesiásticos de María de Velasco. Esto explica también que el arquitecto legase en su tercer testamento quinientos reales al licenciado Guevara. Después, este aparece citado como «capellán de contaduría mayor de S.M.», además de colaborador de primera hora en la Academia de Matemáticas. Recientemente, aunque sin entrar en demasiados detalles, Aramburu-Zabala ha constatado analogías entre el Discurso de Herrera con el «manual» lulista de Guevara, el Arte general y breve, en dos instrumentos para todas las sciencias, recopilado del Arte Magna y Arbor Scientiae del Doctor Raimundo Lulio, editado en Madrid en 1584 (ilustración 2). ${ }^{22}$

En realidad, el Discurso bebe de dos fuentes complementarias, la geometría euclidiana y la combinatoria lulista. Mejor dicho, la primera, que es citada puntual y explícitamente, sirve de introducción a la segunda, que en el caso de Herrera deriva muy probablemente de la síntesis del Ars Magna elaborada por Guevara. Como se ha venido repitiendo, el Discurso es una aplicación de la metafísica luliana a los principios euclidianos de las matemáticas. El mejor resumen de la argumentación herreriana la debemos a los hermanos Carreras y

2. Pedro de Guevara Arte General y Breve. Madrid: 1584, portada. Biblioteca Universitaria de Sevilla.
Artau, quienes remarcaban el carácter denso y difícil de aquellas páginas. ${ }^{23}$ En la primera parte, de contenido estrictamente matemático, se expone la génesis del cubo y el concepto de operación cúbica, mientras que en la segunda, más propia de la filosofía natural, se aplica el Arte luliana para demostrar cómo por la operación cúbica la Naturaleza constituye los entes en el ser. Primero, basándose en la definición euclidiana (libro XI, definición 25: «un cubo es la figura sólida que está comprendida por seis cuadrados iguales»), se muestra la formación del cubo en la cantidad continua, es decir, como cuerpo geométrico; después, de acuerdo con las definiciones 16 a 20 del libro viI del mismo autor, se muestra la formación del cubo en la cantidad discreta, es decir, del número cubo (libro vII, definición 16: «Se dice que un número multiplica a un número cuando el multiplicado se añade a sí mismo tantas veces como unidades hay en el otro y resulta un número»; definición 17: «cuando dos números, al multiplicarse entre sí, hacen algún número, el resultado se llama número plano y sus lados son los números que se han mul-

22. Aramburu-Zabala, M.A., Juan de Herrera, págs. 25 y ss. Guevara es autor de obras gramaticales, pero destaca por sus epítomes de grandes tratados lulianos. Por ejemplo, Breve y sumaria Declaración de la Arte General. Madrid: Pedro Madrigal, 1586.

23. Carreras y Artau, J.; Carreras y Artau, T., Historia de la filosofía española. Filosofía cristiana de los siglos XiII al XV, vol. II. Madrid: C. Bermejo, 1943, págs. 263-267. Véanse también, entre otros, Domínguez ReBoirAs, F., «La recepción del pensamiento luliano en la Península Ibérica hasta el siglo XIX. Un intento de síntesis», Revista de Lenguas y Literatura Catalana, Gallega y Vasca, 15, 2010, págs. 361-385, en particular pág. 377; y VILLALBA, P., Ramon Llull: escriptor i filòsof de la diferència. Bellaterra: Universitat Autònoma de Barcelona, 2015, pág. 510. 
tiplicado entre sí»; definición 18: «Cuando tres números, al multiplicarse entre sí, hacen algún número, el resultado es un número sólido y sus lados son los números que se han multiplicado entre sí»; definición 19: «un número cuadrado es el multiplicado por sí mismo o el comprendido por dos números iguales»; definición 20: «y un número cubo, el multiplicado dos veces por sí mismo o el comprendido por tres números iguales»).

En la segunda parte, que se articula en trece artículos, se intenta demostrar que la generación de un ser natural cualquiera es semejante a la del cuerpo cúbico. Si las dimensiones engendran la figura cúbica y los números el cubo como cantidad discreta, de manera similar los principios absolutos, un reflejo de la divinidad, engendran la plenitud del ser en la criatura mediante su presencia, su operación y la conjunción de ambas. Herrera defiende la tesis de que el cuerpo cúbico, como principio de todo ser natural, es el producto de tres factores, a los cuales corresponde una función distinta — el activo, el pasivo y el conexivo-, que se identifican con los tres correlativos lulianos, -tivum/longitudinal, -bile/latitudinal y-are/profunditudinal, de manera que quedaría probado que en toda criatura existe un vestigio natural de la Trinidad:

y el cubo es el que resulta en acto y individuo de estos tres, Tivo, bile y are, y assí ay en el cubo el agente o activo que es el tivo y el agible o passivo que es el bile y acto o unión de ambos o agere que es el Are, los quales tres, Tivo, bile y are, se llaman los tres corelactivos internos o corelactos intrínsecos, y por modo mathemático se llaman la longitud o línea el Tivo, y la latitud o superficie el bile, y la operaçión de ambos es el are; lo que resulta de esta operaçión se llama el cubo con su longitud, latitud y profundidad, y todos los tres corelactos son su eszençia y natura; y assí como si alguna le faltara era imposible ser cubo, assí también es imposible sin sus tres corelactos naturales tener ningún individuo ser natural [...], y faltando el ser tampoco podría haver obrar, luego repugna a la naturaleça faltar cualquier cosa de los tres corelactos, y mucho más el faltar el último, porque hubiérase sin él criádose la naturaleça en bano, y para no ser lo qual es imposible, porque nunca puediera ser algún individuo sacado de potençia en acto de ser y faltara la relaçión ternaria y el vestigio mayor de la sanctíssima Trinidad en las criaturas, lo qual es imposible.

A esta génesis metafísica del ser en virtud de tales principios o correlativos lulianos Herrera lo llama operación o «penetración» cúbica. Se comprende el alcance de la afirmación de que la figura cúbica es

raíz y fundamento de la dicha arte lulliana y aun de todas las artes naturales subalternadas a ella, porque así como esta figura cúbica tiene plenitud de todas las dimensiones que son en naturaleza igualdad, así en todas las cosas que tienen ser y de que podemos tratar, debemos considerar la plenitud de su ser y de su obra.

En realidad, se intuye que el objetivo de Herrera es superar el aspecto bidimensional de los diagramas del método combinatorio luliano, que se expresa ya sea en forma de tablas, ya sea en forma de círculos concéntricos o ruedas giratorias (figuras), aunque con el mismo objetivo de acercarnos a las características de la divinidad. Por esto, antes de comentar los correlatos, analiza también las dignidades o principios absolutos que según Llull identifican los atributos o principios creativos de Dios. Ya que Herrera se refiere a «los 9 prinçipios absolutos de Raymundo Lullo, que són bondad, grandeça, duraçión, potestad, sabiduría o instinto, voluntad o apetito, virtud, berdad, i gloria o suavidad, i deleytaçión», es evidente que se inspira en la etapa ternaria del Arte (Ars inventiva, Ars generalis ultima), porque en la cuaternaria aumentan a doce dignidades. Esto es así porque pasan a significar la Trinidad, por influencia de san Agustín. ${ }^{24}$ Como asegura Herrera en una carta fechada en 1592, de la que se hablará después,

24. Véase, por ejemplo, Pring-MiLl, R.D.F., Estudis sobre Ramon Llull (1956-1978). Barcelona: Abadia de Montserrat, 1991, págs. 161 y ss.; LlinARÈs, A., «Les dignités divines dans le Libre de contemplació», Catalan Review, 4, 1990, págs. 97-123; 
la doctrina y arte luliana no solamente es inteligible, pero que se puede probar con demostraciones mathemáticas como yo me atreveré a hacerlo, aunque carezco de haber estudiado en las escuelas ni universidades.

Otra prueba evidente del arrebato luliano de Herrera es su biblioteca, cuyo catálogo fue publicado por Ruiz de Arcaute, ${ }^{25}$ y que fue reconstruida virtualmente por Sánchez Cantón. ${ }^{26}$ Sin embargo, este último prescindía prácticamente del fondo luliano («por su índole, el pormenor de ellos interesa a muy contados lectores»), aun reconociendo su singularidad. El verdadero sentido de esta fracción de la librería, que superaba la impresionante cantidad de cien volúmenes sobre un total de cuatrocientos, más o menos, fue dilucidado por Joaquim Carreras y Artau. ${ }^{27}$ La redacción del inventario estuvo supervisada por Juan Arias de Loyola. En resumen, la biblioteca comprendía cuarenta y tres manuscritos con sendas obras de Llull, además de dos apócrifos y una decena de volúmenes con textos de escuela luliana; doce misceláneas de manuscritos de obras de Llull, alguna de las cuales integraba hasta diez piezas; dieciocho volúmenes impresos de autógrafos lulianos, además de cuatro apócrifos y doce de escuela luliana; dos textos lulianos impresos y encuadernados en un solo volumen y otros dos volúmenes con obras manuscritas e impresas. Por contenido, integraba unos sesenta textos manuscritos de Llull en latín (incluidos algunos fragmentarios, equívocos, no catalogados o sin especificar), una docena de manuscritos de Llull en catalán, al menos siete ediciones de Llull (una veintena de volúmenes, publicados en París, Valencia y Barcelona), textos lulianos apócrifos (cuatro sobre retórica, lógica, confesión e Inmaculada; cinco sobre alquimia) y obras de catorce autores de escuela luliana, además de documentos en defensa de la ortodoxia luliana y otros destinados a la incoación del proceso de canonización. En definitiva, se cuentan setenta y un escritos auténticos de Llull diferentes, sin incluir los que no pueden identificarse, diez apócrifos y dieciséis de escuela luliana. Naturalmente, la librería de Herrera era muy variada, como aparece de forma meridiana en el inventario, pero ya en aquel momento se hace hincapié en la importancia del fondo luliano:

una librería de hasta 400 cuerpos de libros de mathemáticas y architectura, y philosophia, y historia y otras sciencias, manuescriptos y de estampa, entre los cuales hay cerca de 100 obras de Raymundo Lulio, manuescriptas y de estampa, que son de mucha estima.

Asimismo, la habitación contenía muebles e instrumentos matemáticos, además de algunas pinturas: una Magdalena de Sánchez Coello, una Piedad de Federico Zuccari y un Ramon Llull anónimo "puesto de rodillas, en hábito de la orden $3^{\text {a }}$ de S. Francisco, de tamaño del natural». ${ }^{28}$ Desde el punto de vista iconográfico, este cuadro no debía alejarse de la imagen que a inicios del siglo XVI Joan Desí pintó en el desmembrado retablo de la Trinidad para el convento de trinitarios de Palma, tabla ahora conservada en la Biblioteca de Catalunya, procedente del fondo Frederic Marès, y anticipa la versión codificada por el pintor Miquel Bestard a inicios del

RuBIO, J.E., Les bases del pensament de Ramon Llull: els orígens de l'art lul-liana. Valencia: Institut Universitari de Filologia Valenciana, 1997, págs. 105 y ss.

25. Ruiz de ArCaute, A., Juan de Herrera..., págs. 150-171, inventario post mortem, 27 de febrero de 1597; reproducido en la edición del Discurso de 1976 (véase n. 1), págs. 430-468. El documento había sido localizado por PÉREz PAsTOR, C., «Noticias y documentos relativos a la Historia y la Literatura españolas. Colección de documentos inéditos para la historia de las Bellas Artes en España», Memorias de la Real Academia Española, tomo XI, vol. II.

26. Sánchez Cantón, F.J., La librería de Juan de Herrera. Madrid: Instituto Diego de Velázquez, 1941.

27. Carreras y ArtaU, J., «El lul-lisme de Juan de Herrera l'arquitecte de l'Escorial», Miscel.lània Puig i Cadafalch, vol. 1. Barcelona: Institut d'Estudis Catalans, 1947-1951, págs. 41-60.

28. Sobre la iconografía de Llull, véase SACARÈs TABERner, M., Vivat Ars Lul-liana. Ramon Llull i la seva iconografia, tesis doctoral. Facultat de Filosofia i Lletres, Universitat Autònoma de Barcelona, 2015. Hasta su publicación, véase, entre otros, GaỲ̀, J. (coord.), Ramon Llull. Història, pensament i llegenda, cat. exp., 30 de octubre de 2008 - 1 de enero de 2009 , Fundació La Caixa, Palma de Mallorca. Barcelona: Obra Social Fundació La Caixa, 2008. 
siglo XVII, cuyo éxito se perpetuó varios siglos. ${ }^{29} \mathrm{~A}$ la vista de la biblioteca y del Discurso, Joaquim Carreras sitúa la espiritualidad de Herrera en la línea del lulismo humanista del círculo de París (Lefèvre d'Étaples, Bouvelles), que se inicia con Nicolás de Cusa y que, ocasionalmente, aparece teñido de intereses alquímicos.

Se preguntaba el mismo autor por la procedencia de los libros lulianos en poder del arquitecto, ya que solo en un caso se especifica que fue «traído de San Martín de Valencia», noticia cuando menos curiosa si se refiere a la iglesia parroquial, ya que lo más habitual era que este tipo de escrito se conservase en librerías conventuales..$^{30}$ Como apéndice, en el ejemplar del Discurso de la Biblioteca Menéndez y Pelayo se incluye una relación detallada de los libros de doctrina luliana existentes en Alcalá (siete en total) y en San Jerónimo de la Murtra de Barcelona (veintiséis en total: catorce en latín, todos manuscritos, excepto dos; otros doce en catalán). Los del monasterio jerónimo eran también conocidos por Dimas de Miguel:

En el monasterio de la Murta de Barcelona hay más de sesenta cuerpos de libros de este autor, entre los quales hay los Contempladores [Libro de contemplación] de este autor, que son libros grandes y de mucha estima.

Pues bien, ahora sabemos que veinticinco de estos volúmenes fueron adquiridos justamente por el arquitecto durante el trienio de 1592-1595:

vint-y-sinch tomos de obras de Ramon Llull que vené aquest convent ab llicència de nostre pare general al senyor Joan de Herrera, trassador major de Sa Magestat, y molt affectat a l'auctor. Los quals enviaren a Castella per orde seu. ${ }^{31}$

Como era de esperar, entre las obras de escuela luliana alojadas en la biblioteca de Herrera eran abundantes las escritas por amigos o conocidos: entre otros, Pedro de Guevara, Dimas de Miguel, Juan Arce de Herrera, Antoni Bellver o Pedro Jerónimo Sánchez de Lizarazo.

En sus últimos años, Herrera se implicó a fondo en los preparativos del proceso de canonización de Llull. Solo o en colaboración con Juan Arias de Loyola, se dedicó a redactar diversos memoriales dirigidos a las autoridades de Mallorca y Cataluña y a los corresponsales en Roma - por ejemplo, el Dr. Antonio Gual- siempre con la finalidad de activar la causa pía. En este sentido, es muy significativo un memorial redactado en solitario el 2 de septiembre de 1595 por orden de Felipe II:

Y porque Su Magestad sabiendo tengo mucha devoción a esta causa y noticia de lo que a ello toca y conviene y dessea tanto la brevedad de su buen subçesso, me mandó hiçiese la instructión siguiente.... ${ }^{22}$

También recababa la documentación necesaria, que aparece registrada en el inventario post mortem, como se ha visto. Los papeles le eran remitidos sobre todo desde Mallorca y Barcelona, en este último caso por el Dr. Juan Vila (1515-1597), canónigo y después obispo de Vic. ${ }^{33}$ Tiene especial importancia la carta que Herrera escribió a primeros de febrero de 1592 al duque

29. Carbonell Buades, M. (coord.), Cendres de Troia. El pintor Miquel Bestard (1592-1633), cat. exp., 23 de febrero - 21 de abril de 2007, Centre de Cultura «Sa Nostra», Palma de Mallorca. Palma de Mallorca: Fundació «Sa Nostra», 2007.

30. Quizá San Martín deba entenderse como topónimo más genérico. Por ejemplo, un famoso pie de imprenta valenciano de la época suele hacer constar «impresso en casa de Pedro Patricio Mey, junto a San Martín».

31. Díaz Martí, C. (ed.), La primera crònica del monestir de Sant Jeroni de la Murtra (1413-1604) de Francesc Talet. Barcelona: Fundació Noguera, 2013, pág. 728. Pero la cita ya era conocida gracias a DuRAN, E. (dir.), Repertori de manuscrits catalans (1474-1620), vol. III. Barcelona: Institut d'Estudis Catalans, 2003, págs. 330-334.

32. Pérez Martínez, L., «Nuevos documentos sobre el lulismo de Juan de Herrera», Estudios Lulianos, 14/1, 1970 , págs. 71-82.

33. Muntaner Bujosa, J., «Documentos Lulianos», Bolletíde la Societat Arqueològica Lul.liana, XxVIII, 674, 1939, págs. 43-54; PÉrez Martínez, L., «La causa luliana...»; ídem, Els fons manuscrits lul.lians de Mallorca. Barcelona: Universitat de Barcelona - Universitat de les Illes Balears, 2004, docs. 419, 442, 443, 459, 502, y 509. 
de Sessa, embajador extraordinario en Roma, transcrita y solo parcialmente publicada por Lorenzo Pérez. ${ }^{34}$ El texto comienza y termina con una verdadera declaración de principios lulianos:

Yo ha muchos años que me aficioné y tuve voluntad de entender la doctrina, méthodo y arte de Raimundo Lullio, de quien creo V.E. tiene particular relación por el Dr. Arce de Herrera, ya difunto, que en esa Corte romana, con poder de los tres Reinos de Aragón, Cataluña y Valencia, defendía la dicha doctrina [...]. Todo este trabajo me atrevo a dar a V.E. y a suplicar lo tome en las cosas tocantes a Raymundo Lullio porque sé cierto el mérito que desto se podrá seguir y el bien que V.E. hará a la cristiandad. Y podrá V.E. afirmar que la doctrina y arte luliana no solamente es inteligible, pero que se puede probar con demostraciones mathemáticas, como yo me atreveré a hacerlo, aunque carezco de haber estudiado en las escuelas ni universidades. Y más sé decir V.E. que es impossible de toda impossibilidad poderse saber bien sabida la filosofía si no se han penetrado o se penetran bien los principios de Raymundo... Assí que V.E. por amor de Dios se haga protector y amparador desta doctrina, porque hará a Dios un grande servicio y al mundo un grande bien, assí en las cosas naturales como en las morales. Y pues S.M. había escrito a V.E. que esto se tratasse con el Sumo Pontífice, pidiendo que se guardasse la justicia al arte de Raymundo, V.E. tome la mano y lo acabe, pues es propio de valor y grandeza de V.E. emplearse en cosas tan graves y de tanta calidad.

Por lo que se deduce de los escritos y memorias de su periodo de reclusión en Mallorca, Jovellanos no estaba especialmente interesado por el pensamiento de Llull. Además, probablemente por influencia del padre Feijoo, ${ }^{35}$ prefiere ser cauto respecto a la ortodoxia lulista de Herrera, de quien se confesaba ferviente admirador ${ }^{36}$ Recordemos que el benedictino se había mostrado muy crítico con la doctrina luliana, ${ }^{37}$ polemizando con sus abogados, sobre todo con el cisterciense padre Pasqual. ${ }^{38}$ La reticencia de Jovellanos se hace patente en una carta dirigida al archivero y presbítero José Barberí, en la que le comenta las posibles virtudes del lulismo: «Por fortuna, con un poco de maña se puede seguir el espíritu de esta escuela, sin mezclarse en las delicadas cuestiones de culto, las cuales debe usted evitar con el mayor cuidado, so pena de anatema». ${ }^{39}$ Acorde con el escepticismo de Feijoo, Jovellanos necesitaba justificar el lulismo de Herrera como algo puntual y sin mayor trascendencia, poco más que un divertimento matemático. En su apéndice al Discurso de Herrera (fols. 155-157), el gijonés insiste en los peligros de la heterodoxia del mallorquín y establece una clara distinción entre doctrina y método, punto este último en que se situaría el arquitecto:

Mas por fortuna se puede discurrir acerca del escrito de Herrera sin tomar partido en tal materia y esto haré yo, trataré la histórica y no polémicamente; y colocándome entre los dos partidos, sin adoptar ni desechar la doctrina lulliana, y sin decirla celestial y inspirada como unos, ni condenada y herética como otros, haciendo a su venerable autor el honor y justicia que son debidos a su eminente ingenio, me reduciré a descubrir el camino por donde pudo venir Herrera a conocer su arte y ser alumno suyo. Pero ante todas las cosas haré una prevención tan conducente a mi propósito como necesaria para evitar los errores y paralogismos en que por falta de ella han caído, así los que defendieron como los que censuraron al Maestro Raymundo Lull. No debe confundirse el arte o método de este insigne autor con su doctrina. Puede ser ésta buena sin que aquél lo sea, y puede ser bueno su método sin que de aquí se infiera que lo son sus opiniones [...]. Supuesta esta prevención,

34. PÉrez Martínez, L., «La causa luliana...», págs. 213-214.

35. MuÑIZ, M.E., «Proyección del pensamiento de Feijoo en Jovellanos», Boletín Jovellanista, 4, 2003, págs. 37-48.

36. López SuÁRez, L., «Jovellanos, Herrera y El Escorial», en CAmpos y Fernández de Sevilla, FJ. (coord.), Literatura e imagen en El Escorial. Actas del Simposium, 1-4 de septiembre de 1996, San Lorenzo de El Escorial. San Lorenzo de El Escorial: Real Centro Universitario Escorial - María Cristina, 1996, págs. 405-431.

37. FeIJoo, B.J., Cartas eruditas y curiosas, vol. I. Madrid: Herederos de Francisco del Hierro, 1742, carta 22 «Sobre la arte de Raimundo Lulio», págs. 190-193; ibidem, vol. III, carta 26 «Respuesta al Rmo. P. M. Fr. Raymundo Pasqual en asunto de la doctrina de Raymundo Lulio»; véase Colombàs, G.M., «Feijoo y el lulismo», Studia Lulliana, 7, 1963, págs. 113-130.

38. PAsqual, A.R., Examen de la crisis del Rumo. Padre Maestro D. Benito Gerónymo Feyjóo, monge benedictino, sobre el Arte Luliana, en la que se manifiesta la santidad y culto del B. Raymundo Lulio, Doctor Iluminado y Mártyr, pureza de su doctrina y la utilidad de su arte, claramente explicada, 2 vols. Madrid: Imprenta de Lorenzo Francisco Mojados, 1749-1750.

39. Jovellanos, G.M. DE, Obras publicadas e inéditas, vol. 2. Madrid: Rivadeneyra, 1858-1859, pág. 155. 
es de saber que el discurso de Juan de Herrera no versa sobre la doctrina, sino sobre el método lulliano, y que por tanto no se puede decir de él que adoptó la doctrina, sino el método de R. Lull. Es verdad que el arte magna no consiste sólo en el artificio, sino también en los principios o términos establecidos por Lull, y que Herrera adoptó uno y otro. Pero estos llamados principios no son doctrinales, sino metódicos; y Lull los estableció y Herrera los adoptó no como elementos de alguna ciencia, sino como términos o medios de un método dispuesto para estudiarlas todas.

Pero ahora sabemos que Jovellanos no disponía de suficiente información sobre la dimensión doctrinal del lulismo herreriano y, por tanto, se equivocaba. Y es que todos los indicios apuntan a un protagonismo inaudito del arquitecto en la defensa de la espiritualidad luliana, actuando siempre con el apoyo tácito, si no la complicidad, de Felipe II. Un problema muy distinto, muy debatido y que desborda la posibilidad de estas líneas es el del posible reflejo que esta inclinación pudo tener en la obra arquitectónica. El debate fue abierto hace cincuenta años por René Taylor, ${ }^{40}$ un hispanista británico muy influido por los estudios de Rudolf Wittkower sobre las proporciones armónicas en la arquitectura renacentista, y los de Frances A. Yates sobre el lulismo humanista y el pseudolulismo alquímico — el cual, por otra parte, tiende a desaparecer en España a lo largo del último tercio del siglo xvi debido a los intentos de los prosélitos de expurgar el corpus de Llull de cualquier posible disensión confesional e impulsar el proceso de canonización, fenómeno que Taylor y otros tienden a obviar-. ${ }^{41}$ Después, la polémica ha pivotado en torno a un argumento paralelo, el «salomonismo» y el simbolismo bíblico de El Escorial, aunque parece claro que se trata de un significado superpuesto a última hora por Benito Arias Montano. En cambio, el lulismo y el Discurso se han convertido en lugares comunes de la literatura herreriana, sin que se haya profundizado en el tema. O se ha malinterpretado, como hace Catherine Wilkinson Zerner en una famosa monografía sobre el arquitecto, sin duda porque no es cierto que «Herrera's teatrise is the only direct evidence of his personal views on Lull». ${ }^{42} \mathrm{O}$ bien cuando se quiere asimilar el Discurso con otras disquisiciones sobre la figura cúbica, sobre todo en relación con Luis de Lucena y los debates vitruvianos de la romana Accademia della Virtù, como recuerda Guillaume Philandrier en sus Annotationes in Vitrubium. Pero el problema que querían resolver estos eruditos era de carácter estrictamente geométrico, la duplicación del cubo, uno de los tres famosos retos matemáticos de la Antigüedad, junto a la cuadratura del círculo y la trisección del ángulo, irresolubles con regla y compás, ya que implican números irracionales. Tampoco es aceptable la interpretación, polémica, de Maria Calí, según la cual

el Discurso de Herrera no nace, como se ha creído, del pretexto de exponer de nuevo las ideas del filósofo mallorquín, sino del propósito de comprobar la importancia de la forma cúbica de Miguel Ángel a la luz de tales ideas.

De manera que, «en su tratado Herrera no hizo más que dar un revestimiento teórico a una elección de carácter estilístico-formal». ${ }^{43}$ Muy al contrario, el cubo de Herrera es luliano, metafísico y trinitario (ilustración 3).

40. TAYLOR, R., Arquitectura y magia... Una primera versión fue publicada anteriormente en Essays in the History of Architecture presented to Rudolf Wittkower. Londres: Phaidon, 1967, págs. 81-109; y en Traza y Baza, 6, 1976, págs. 5-62.

41. Por ejemplo, niega que Herrera pudiera distinguir entre el Llull auténtico y las imposturas lulianas de carácter alquímico y cabalístico. Véase TAYLOR, R., «Juan Bautista Villalpando y Jerónimo de Prado: de la arquitectura práctica a la reconstrucción mística», en Ramírez, J.A. (ed.), Dios arquitecto. J.B. Villalpando y el Templo de Salomón. Madrid: Siruela, 1994, págs. 153-211. Pero ya en 1572 el arquitecto escribía en un billete a Felipe II, «aunque tengo estas cosas de Alchimia por burla...». Acompañaba un memorial de un alquimista llamado Juan Fernández, que el rey despachó de manera similar y expeditiva («y yo lo tengo y he tenido siempre por cosa de burla»).

42. Cito por la edición original, Wilkinson Zerner, C., Juan de Herrera. Architect to Philip II of Spain. New Haven Londres: Yale University Press, 1993 (edición en español: Akal, Madrid, 1996; véase n. 9). Dedica un breve capítulo a la Divina Proporción y al lulismo, que califica reductivamente de «a special branch of the Neo-Platonic tradition».

43. En esta línea, entre otros, CALÍ, M., De Miguel Ángel a El Escorial. Momentos del debate religioso en el arte del siglo XVI. Madrid: Akal, 1994 (1980); ídem, «El Escorial, la figura cúbica de Herrera y Miguel Ángel», Academia, 63, 1986, págs. $185-218$. 


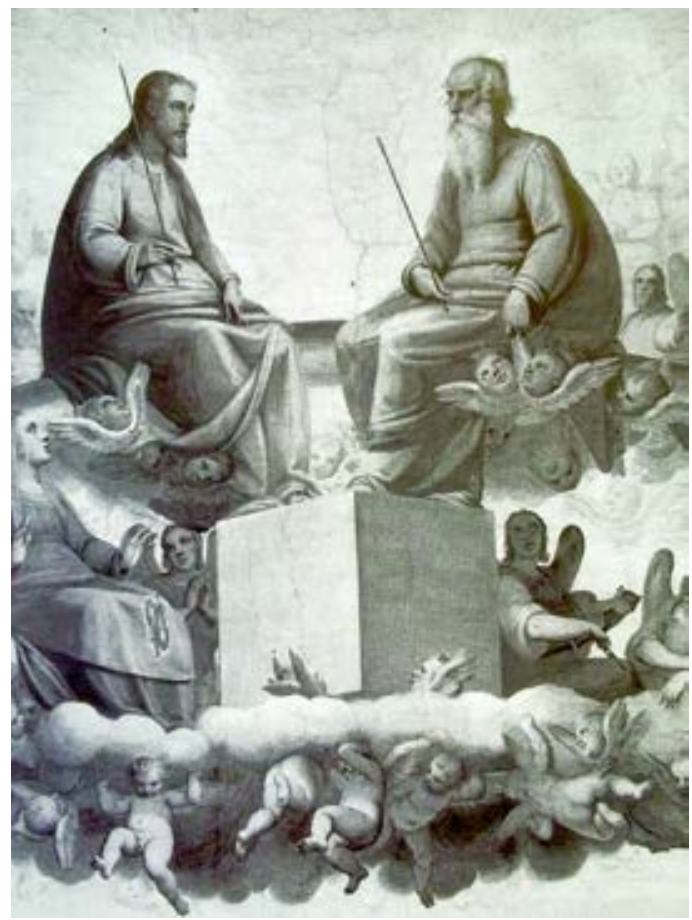

3. Luca

Cambiaso

La Gloria

(detalle), 1584, pintura mural, bóveda del coro de la basílica del Real Sitio de San Lorenzo de El Escorial.
Es sorprendente que ninguno de estos autores se haya interesado por conocer mejor el contenido de la librería herreriana, en particular su fondo luliano, y prefieran tomar la parte - esotérica, alquímica, cabalística - por el todo. Ni que hayan sentido la tentación de recoger más datos sobre la intervención del arquitecto en los preliminares de la causa pía. No se trata solo de que Herrera poseyera muchos libros de Llull, sino que escogiera las obras de mayor enjundia filosófica y doctrinal: Liber contemplationis in Deum, Arbor scientiae, Liber de natura, Liber de lumine, Ars compendiosa, Liber principiorum phylosophiae, Liber chaos, Ars inventiva veritatis, Rethorica nova, Logica brevis, Liber de ascensu et descensu intellectus, Ars brevis, Arts generalis ultima, Methaphysica nova et compendiosa, Liber de Trinitate et Incarnatione, etc., solo por citar algunos de los manuscritos en latín. El lulismo de Herrera no fue nunca circunstancial, como pudo serlo después en Lope de Vega, según se reconoce en la Égloga a Amarilis: «Aquí luego engañó mi pensamiento / Raymundo Lulio, labirinto grave, / rémora de mi corto entendimiento». Pero el lulismo sustancial del arquitecto era ya reconocido por Menéndez y Pelayo, a quien nadie cita, por cierto, dejando de lado su indisimulado entusiasmo:

Espíritu vigoroso y sintético, complacíase Herrera en altas especulaciones, invadiendo a veces el terreno de la Metafísica [...]. Sea cualquiera el juicio que se forme de la cábala matemática, que es accesoria en esta especulación, hay un pasaje de este desconocido tratado [el Discurso] en que es imposible negar el valor y la alteza de la especulación metafísica, y dejar de conceder al insigne arquitecto montañés lugar muy aventajado entre los filósofos armónicos de nuestro siglo XVI, cuando le vemos afirmar, con inquebrantable firmeza de ontologista, que «son los principios absolutos necesarios en cualquier arte, porque sin ellos no podría ser, ni obrar, ni haber esencialmente cosa alguna, y a éstos, como a fuentes universales, se reducen todos los demás que puede hallar el humano entendimiento, porque en éstos están implícitos, y ansí todos se han de reducir y aplicar a éstos». Verdadera profesión de realismo metafísico bastante para demostrarnos que Juan de Herrera había penetrado quizá, más que ningún otro luliano, en las entrañas de la filosofía del Beato Ramón, sorprendiendo el principio universal que la informa y da valor, y prescindiendo de las combinaciones dialécticas o sustituyéndolas por otras. ${ }^{44}$

En cuanto a la posible traducción arquitectónica del cubismo lulista de Herrera, si puede llamarse así, será suficiente recoger la opinión de Fernando Marías, ${ }^{45}$ según el cual, aunque el Discurso nunca aluda a la arquitectura, hemos de suponer que la especulación filosófica del arquitecto tuvo que tener necesariamente repercusiones en su quehacer artístico. Después de todo, el cubo herreriano es metáfora de todas las cosas y a la vez un principio de construcción formal, tanto de carácter técnico como simbólico.

\footnotetext{
A partir de su origen en Miguel Ángel, y en el marco de la Contrarreforma, la autora interpreta la forma cúbica como principio estilístico y como emblema ideológico y espiritual, supuestamente perpetuados en El Escorial gracias a la transmisión «cubizante» de algunos alumnos del florentino en Roma llamados a la corte de Felipe II, aunque en una versión «programáticamente reductiva». Las tesis de Calí son una impugnación a las interpretaciones en clave vitruviana de El Escorial.

44. Menéndez y Pelayo, M., Historia de las ideas estéticas en España, Biblioteca Virtual Menéndez Pelayo de la Biblioteca Virtual Ignacio Larramendi de Polígrafos, Madrid, 2012, págs. 2190-2191.

45. MARías, F., El siglo XVI. Gótico y Renacimiento. Madrid: Sílex, 1992, págs. 210-211.
} 